Document downloaded from:

http://hdl.handle.net/10251/38710

This paper must be cited as:

Ferre Aracil, J.; Cardona Navarrete, SC.; López Pérez, MF.; Abad Sempere, A.; NavarroLaboulais, J. (2013). Unstationary Film Model for the Determination of Absolute Gas-Liquid Kinetic Rate Constants: Ozonation of Acid Red 27, Acid Orange 7, and Acid Blue 129. Ozone: Science and Engineering. 35:423-437. doi:10.1080/01919512.2013.815104.

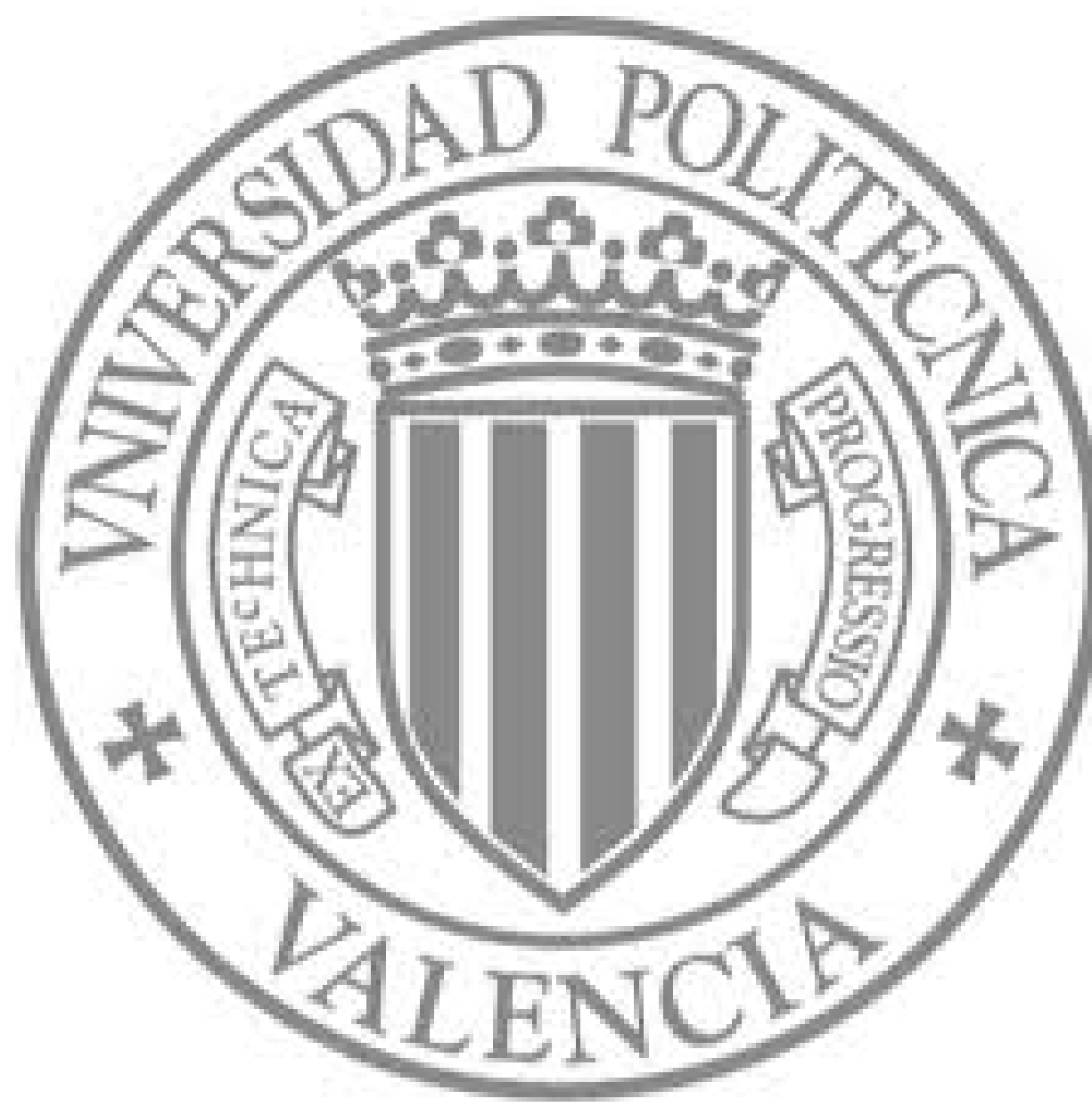

The final publication is available at

http://www.tandfonline.com/doi/abs/10.1080/01919512.2013.815104\#.U4X4g3brxL0

Copyright

Taylor \& Francis: STM, Behavioural Science and Public Health Titles 


\title{
Unstationary Film Model for the Determination of Absolute Gas-Liquid Kinetic Rate Constants. Ozonation of Acid Red 27, Acid Orange 7 and Acid Blue 129
}

\author{
J. Ferre-Aracil, S.C. Cardona, F. López, A. Abad, J. Navarro-Laboulais
}

Universitat Politècnica de València - EPSA. Department of Chemical and Nuclear Engineering. Pl. Ferrandiz i Carbonell , 03801 Alcoy, Alicante, (Spain).

Phone: +34 963877633. Fax: +34963877639 e-mail: jnavarla@iqn.upv.es

Received for review:

Accepted for publication 


\title{
Unstationary Film Model for the Determination of Absolute Gas-Liquid Kinetic Rate Constants. Ozonation of Acid Red 27, Acid Orange 7 and Acid Blue 129
}

\author{
J. Ferre-Aracil, S.C. Cardona, F. López, A. Abad, J. Navarro-Laboulais \\ Universitat Politècnica de València - EPSA. Department of Chemical and Nuclear \\ Engineering. Pl. Ferrandiz i Carbonell , 03801 Alcoy, Alicante, (Spain). \\ Phone: +34 963877633. Fax: +34963877639 e-mail: jnavarla@iqn.upv.es \\ Received for review: \\ Accepted for publication
}

\begin{abstract}
A method for the determination of absolute kinetic rate constants is proposed using an unstationary film model. This methodology avoids the experimental determination of parameters like the enhancement factor or the Hatta number which are usually model-dependent. The mathematical model is general for gasliquid systems with irreversible second order reactions. An optimization procedure based on artificial neural networks is used to estimate the initial guess of the parameters and the subsequent application of Gauss-Newton algorithm for the final non-linear parameter estimation. The model is tested with the ozonation reaction of Acid Red 27, Acid Orange 7 and Acid Blue 129. The second order kinetic rate constant for the direct reaction with $\mathrm{O}_{3}$ are $1615 \pm 93,609 \pm 83$ and $49 \pm 2 \mathrm{M}^{-1} \mathrm{~s}^{-1}$ respectively.
\end{abstract}

\section{1.- Introduction}

The kinetic rate constants are the key parameters for design and scale-up of Bubble Column Reactors (BCR). Although there is a general consensus about the experimental methods and the numerical data treatment for the determination of 
physical constants related to $\mathrm{BCR}$, i.e., gas hold-up, $\varepsilon$, volumetric mass transfer coefficient, $k_{L} a$, specific interfacial area, $a$, and bubble size, $d_{32}$ or $r_{32}$, there is less agreement about the kinetic rate constants determination methods and their numerical values. The common theoretical framework used in the analysis of the experimental data for kinetic rate constants determination is usually the stationary Lewis-Whitman film model or the surface renewal theories of Higbie and Danckwerts, where the kinetic rate constants are determined from the calculated enhancement factor, $E$. This procedure is only valid when the gas-liquid reactor is operating under steady state conditions, circumstance which is not always checked, nor assured. This is especially true in semi-batch bubble column reactors where, by definition, the system is always under unstationary conditions.

Assuming a behaviour as a perfectly mixed stirred tank for the liquid phase and plug flow (PF) for the gas phase in an ozonation semi-batch reactor, the mass balance of the gas phase, neglecting the accumulation term, allows the determination of the enhancement factor by (Rapp and Wiesmann, 2007; Lopez et al., 2004):

$$
E k_{L} a(t)=\frac{Q_{0}}{V} H_{I O A} \ln \left(\frac{C_{\text {in }}-H_{I O A} \cdot C_{l}(t)}{C_{\text {out }}(t)-H_{I O A} \cdot C_{l}(t)}\right)
$$

Where $Q_{0}$ is the gas flow rate, $V$ the volume of liquid, $H_{I O A}$ is the Henry's constant recommended by the IOA (Bin, 2006), $C_{\text {in }}$ and $C_{\text {out }}(t)$ are the inlet and outlet ozone gas concentrations respectively and $C_{l}(t)$ is the concentration of the dissolved ozone in the liquid phase. Assuming that the reaction is fast, the concentration in the liquid remains low along the experiment and thus from [1] we deduce that the enhancement factor is proportional to the logarithm of the input and output ozone concentrations ratio. Although eq. [1] has been used for the determination of $E$, its use under unstationary (semi-batch) conditions for bubble-columns is not mathematically consistent because a stationary hypothesis is applied to an unstationary situation. Following the eq [1], as the chemical reaction progresses the ozone gas concentration at the output of the reactor, $C_{\text {out }}(t)$, approaches its input concentration, $C_{\text {in }}$, i.e. $C_{\text {out }}(t \rightarrow \infty)=C_{i n}$, and then, from [1] it is deduced that the enhancement factor vanishes under these circumstances. This fact disagrees with the rigorous definition of the enhancement factor which implies that $E \geq 1$ (Danckwerts, 1970).

The enhancement factor gives us information about the mass transfer across the interface in a gas-liquid reacting system. Moreover, it is related with the position of the reacting plane in the liquid film, position which will change with the time as the chemical reaction progresses under unstationary conditions. For fast chemical reactions, the reaction plane is located near the gas-liquid interface and moves to the bulk solution as the reactant concentration vanishes enough to decrease the instantaneous Hatta number. Different expressions relating the enhancement factor 
with the kinetic constants under different kinetic regimes have been proposed (Doraiswamy and Sharma, 1984). These expressions were derived considering, for instance, different hypothesis about the position of the reaction plane or the concentrations of the reacting species in the bulk. But these hypotheses, always done in steady state conditions, are no longer valid under unstationary conditions because we expect that the reaction plane moves from the gas-liquid interface to the liquid bulk, changing the kinetic regime from the instantaneous to the slow one and all the intermediates.

Additionally to this inconsistency, the enhancement factor is related with the kinetic rate constants in a complex way. Depending on several physical and chemical considerations about our reactive system, the equations for the estimation of the enhancement factor are different, being only very few of them a rigorous analytical solution of the mathematical formulation of the problem. For instance, the enhancement factors for a first and second order irreversible chemical reaction are respectively (Danckwerts, 1970; Beltrán, 2004):

$$
\begin{gathered}
E=H a_{1}\left(\beta \cdot \operatorname{Coth} H a_{1}-(\beta-1) \cdot \operatorname{Csch} H a_{1}\right) \\
E=\frac{H a_{2}\left(\frac{E_{i}-E}{E_{i}-1}\right)^{1 / 2}}{\operatorname{Tanh}\left[H a_{2}\left(\frac{E_{i}-E}{E_{i}-1}\right)^{1 / 2}\right]}
\end{gathered}
$$

where $H a_{1}$ and $H a_{2}$ are the Hatta numbers for the first and second order reactions respectively, $E_{i}$ the instantaneous enhancement factor and $\beta$ is related with the ozone saturation and bulk concentrations, respectively (Beltrán, 2004). While the eq. [2] is valid for all first order reactions but with the chemical reaction only inside the liquid film, eq. [2] is valid only when the concentration of the transferred gas in the liquid bulk is zero, i.e., $C_{A}^{b}=0$. Notice also that while $E$ determined by experiments with an unstationary BCR and using eq. [1] is a function of time, the eqs. [2] and [3] are defined under steady state conditions. In fact, if there is any variation in the bulk concentration with time, the eqs. [2] and [3] cannot be derived because the boundary conditions needed to obtain these equations imply constant concentrations there. Under unstationary conditions such as in semi-batch BCR these constant boundary conditions cannot be ensured, and thus the physical meaning of $E$ in eqs [2] and [3] is not the same that in eq [1].

In order to overcome these problems, in this work we propose to describe an unstationary film model for a bubble-column reactor operating in semibatch conditions allowing the direct estimation of the kinetic rate constants without the intermediate calculation of the enhancement factor. The model is based on the quiescent film model 
assuming a second order irreversible chemical reaction. The method of lines (Zwillinger, 1998) is used to obtain a numerical version of the model allowing the fitting of experimental data using the Gauss-Newton algorithm (GN) (Englezos and Kalogerakis, 2001), considering a new methodology based on artificial neural networks (ANN) to estimate the initial guesses. Although the model is general for any gas-liquid reacting system, in this work we show the results of the ozonation reaction with some azo-dye compounds. The paper has been structured as follows. First the description of the unstationary mathematical model for the reacting gas-liquid system is shown. Then, the optimization procedure used for kinetic rate constant determination is outlined. It follows the description of material and apparatus designed for the experiments and, finally, the results together with their discussion are shown.

\section{2.- The mathematical model}

For the development of gas-liquid transfer models coupled with chemical reactions, few theories could be considered to describe the phenomena near the interface (Glasscock and Rochelle, 1989): (a) the Quiescent Film Theory: proposed by Lewis and Whitman (1924), which postulates that the mass transfer through the interface proceeds by molecular diffusion in a rigid film of thickness $\delta$ near the contact surface between gas and the liquid; (b) the Penetration Theory: originally proposed by Higbie (1935) it is an essentially non-stationary theory where the transfer takes place in volume elements coming from the liquid bulk and staying at the interface for a time, $\theta$, called contact time; (c) the Surface Renewal Theory: initially proposed by Danckwerts (1970) and modifies Higbie's theory considering that there is a probability distribution function for contact times where the volume elements are renewed at some renewal rate, $s$; (d) the Eddy-Diffusion Theory: proposed by King (1966) and where the diffusion coefficient considered in the above theories is modified to consider the turbulent transport due to the agitation of the fluids; and (e) the Modified Quiescent Film Theory: consists of a modification of the film theory proposed by Chang and Rochelle (1982) where the values of the diffusion coefficients are corrected in a way that the Film Theory solution for the mass transfer approaches those predicted by Penetration and Surface Renewal theories.

The previous theories can be discriminated each other by analyzing the dependence of the mass transfer coefficient with the diffusion coefficient of the transferred gas. While the film theory predicts a linear proportional relationship between both factors, the penetration and surface renewal theories together with the modified film theory, predict a relationship as $k_{\mathrm{L}} \sim D^{1 / 2}$; the prediction in the eddydiffusion theory depends on the turbulence model chosen to describe the interface (Glasscock and Rochelle, 1989). Since it is difficult to demonstrate empirically all these points because of the limited range of variation for the diffusion coefficients of gases in liquids, renewal theories are commonly accepted as the most suitable to 
represent the mass transfer processes in gas-liquid interfaces (Danckwerts, 1970). However and considering the conceptual closeness between the film and renewal theories (Meldon et al., 2007), these two theories have been the most commonly used to model the mass transfer processes coupled to chemical reactions. Additionally, the film model can be integrated in a macroscopic reactor model for the dynamic description of the experimental observations while, with the surface renewal theories, this cannot be done in such a straightforward way.

Let us consider the following general restrictions for our gas-liquid unstationary model: i) the hydrodynamic flow of the gas and liquid bulk in the reactor has been considered as CSTR for the gas phase and perfectly mixed for the liquid phase; ii) the gas film resistance has been considered negligible under the operating conditions and, consequently, the molecular diffusion in the liquid film is the only resistance to mass transport across the interface; iii) ideal gas and Henry laws are valid under the operating conditions; iv) there is only two reacting species, A and B, where $\mathrm{A}$ is the gas transferred to the liquid and B is a non-volatile substance dissolved in the liquid; v) a global second order irreversible chemical reaction is considered together with unitary stoichiometric coefficients:

$$
\mathrm{A}(g \rightarrow l)+\mathrm{B}(l) \stackrel{k_{2}}{\longrightarrow} \operatorname{Products}(l)
$$

For describing the mass-transfer phenomenon through the gas-liquid interface, a quiescent liquid film is considered separating the gas and the liquid bulk. Inside this liquid film of length $\delta$, the substances are spatially distributed as a result of the diffusion-reaction processes. Assuming an unstationary diffusion-reaction equation to model the mass transport across the film with constant diffusion coefficients, the mass balances of ' $A$ ' and ' $B$ ' in the gas, the film and the bulk phases lead to the following coupled system of ordinary and partial differential equations (Navarro-Laboulais et al. 2006; Cardona et al., 2010)):

$$
\begin{gathered}
\frac{d y(t)}{d t}=\frac{Q\left(1-y_{i n}(t)\right)}{V} \frac{1-\varepsilon}{\varepsilon}\left(\frac{y_{i n}(t)}{1-y_{i n}(t)}-\frac{y(t)}{1-y(t)}\right)+\frac{R T}{P} \frac{1}{\varepsilon} D_{A} a\left(\frac{\partial C_{A}(z, t)}{\partial z}\right)_{z=0} \\
\frac{\partial C_{A}(z, t)}{\partial t}=D_{A} \frac{\partial^{2} C_{A}(z, t)}{\partial z^{2}}-k_{2} C_{A}(z, t) C_{B}(z, t) \quad \forall z \in[0, \delta] \\
\frac{\partial C_{B}(z, t)}{\partial t}=D_{B} \frac{\partial^{2} C_{B}(z, t)}{\partial z^{2}}-k_{2} C_{A}(z, t) C_{B}(z, t) \quad \forall z \in[0, \delta] \\
\frac{d C_{A}^{b}(t)}{d t}=-\frac{D_{A} a}{1-\varepsilon}\left(\frac{\partial C_{A}(z, t)}{\partial z}\right)_{z=\delta}-k_{2} C_{A}^{b}(t) C_{B}^{b}(t) \\
-6-
\end{gathered}
$$




$$
\frac{d C_{B}^{b}(t)}{d t}=-\frac{D_{B} a}{1-\varepsilon}\left(\frac{\partial C_{B}(z, t)}{\partial z}\right)_{z=\delta}-k_{2} C_{A}^{b}(t) C_{B}^{b}(t)
$$

where $y(t)$ stands for the mole fraction of $\mathrm{A}$ in the gas phase, $C_{A}$ and $C_{B}$ are the concentrations at the liquid film and $C_{A}^{b}$ and $C_{B}^{b}$ are the concentrations at the liquid bulk. $D_{A}$ and $D_{B}$ are the diffusion coefficients for 'A' and 'B' respectively, $k_{2}$ is the second order kinetic rate constant, $Q$ the gas flow rate, $V$ the liquid volume, $\mathcal{E}$ the gas hold-up and finally, $T$ and $P$ are the temperature and pressure inside the reactor respectively. Because the gas-liquid interface is not accessible to measurement, the only observable state variables of the system of equations [5]-[9] are $y(t), C_{A}^{b}$ and $C_{B}^{b}$.

A scheme of the reactor used in the experiments is shown in Fig. 1. The central part or the reactor is where the gas-liquid transfer and chemical reactions take place and where the eqs. [5]-[9] are defined, while the lower and upper control volumes shown on Fig. 1 are usually a mixing-gas chamber and the reactor head-space respectively. Since almost all the gas-liquid reactors, and particularly all the bubblecolumn reactors, have this configuration, it is necessary to append to the precedent system of ordinary and partial differential equations the equations describing the gas dilution into these two chambers. Thereby, for the gas-mixing chamber at the bottom of the reactor, the mass balance gives:

$$
y_{\text {in }}(t)=y_{A 0}\left(1-\exp \left(-\frac{Q}{V_{B}} t\right)\right)
$$

while for the head-space at the upper part, the mass balance leads to:

$$
\frac{d y_{\text {out }}(t)}{d t}=\frac{Q}{V} \frac{1-\varepsilon}{(1-\varepsilon) \frac{V_{R}}{V}-1}\left(1-y_{\text {in }}(t)\right)\left(\frac{y(t)}{1-y(t)}-\frac{y_{\text {out }}(t)}{1-y_{\text {out }}(t)}\right)
$$

In eqs. [10] and [11], $V_{\mathrm{B}}$ is the volume of the gas-mixing chamber and $V_{R}$ the total volume of the reactor $\left(V_{C}+V_{F}\right)$. 


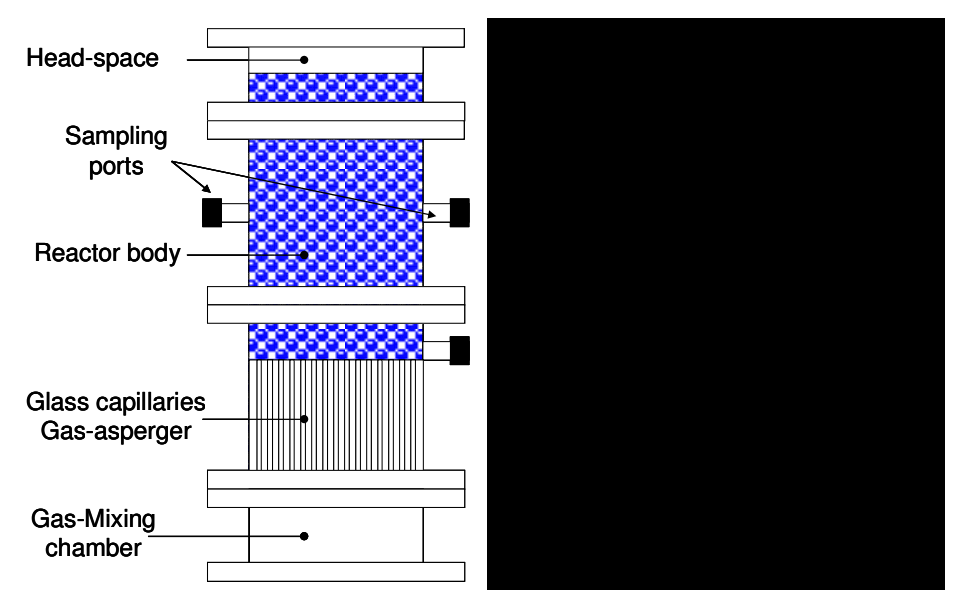

Fig. 1 Schematic diagrams for the gas-liquid reactor described in the experimental section. At left, the different parts of the reactor, while at right, the diagram shows the Control Volumes (CV1, CV2, CV3), the gasmolar fluxes $\left(F_{0}, F_{1}, F_{2}, F_{3}\right)$ and mole fractions at gas phase $\left(y_{\mathrm{A} 0}, y_{\text {in }}, y\right.$, $\left.y_{\text {out }}\right)$ used for the mathematical description of the reactor.

Together with eqs. [5]-[11] a set of initial and boundary conditions defines uniquely the mathematical problem. All the initial conditions of the model are zero except for the variables $C_{B}$ and $C_{B}^{b}$ which are equal to the dye initial concentration $C_{B 0}$. The initial and boundary conditions are:

$$
\begin{gathered}
y_{\text {in }}(0)=y(0)=y_{\text {out }}(0)=C_{A}(z, 0)=C_{A}^{b}(0)=0 \\
C_{B}(z, 0)=C_{B}^{b}(0)=C_{B 0} \\
C_{A}(0, t)=\frac{P}{H_{I O A}} y(t) \quad C_{A}(\delta, t)=C_{A}^{b}(t) \\
\left(\frac{\partial C_{B}(z, t)}{\partial z}\right)_{z=0}=0 \quad C_{B}(\delta, t)=C_{B}^{b}(t)
\end{gathered}
$$

The conditions [13.a] ensure, for the component A, the equilibrium between the gas and the liquid phase at the interface through the Henry's constant, $H_{I O A}$, and the continuity between the liquid film and the liquid bulk. In addition, the conditions [13.b] express the non-volatility of ' $\mathrm{B}$ ' and the continuity between the liquid film and the liquid bulk. 
No rigorous analytical solution of the system [5]-[13] can be envisaged by conventional mathematical techniques because of the coupling of the non-linear ordinary and partial differential equations with the mixed boundary conditions. A numerical approximation of the solution can be evaluated using the method of lines applied to eqs. [5]-[9] along the spatial coordinate, $z$, using second-order forward, backward and central differences schemes for the flux terms (Zwillinger, 1998). With this method, the liquid film is divided in $N$ equally spaced slabs where the derivatives in each point are estimated using finite difference formulas. Furthermore, considering the input gas mole fraction, $y_{A 0}$, the saturation concentration of the transferred gas, $C^{*}=y_{A 0} \frac{P}{H_{I O A}}$ and the initial dye concentration, $C_{\mathrm{B} 0}$, we can define the dimensionless concentration for ' $\mathrm{A}$ ' as:

$$
\left\{\begin{array}{c}
x_{0}=\frac{y_{\text {in }}(t)}{y_{A 0}} \quad ; \quad x_{1}=\frac{y(t)}{y_{A 0}} \\
x_{i}=\frac{C_{A i}}{C^{*}} \quad i=2, \ldots, N \\
x_{N+1}=\frac{C_{A}^{b}}{C^{*}} \quad ; \quad x_{2 N+2}=\frac{y_{\text {out }}(t)}{y_{A 0}}
\end{array}\right.
$$

where $x_{i}$ is the dimensionless concentration of ' $\mathrm{A}$ ' at the $i$-th slab which the liquid film has been divided. For ' $\mathrm{B}$ ' we define its dimensionless concentration as:

$$
x_{j}=1-\frac{C_{B j}}{C_{B 0}} \quad j=N+2, \ldots, 2 N \quad ; \quad x_{2 N+1}=1-\frac{C_{B}^{b}}{C_{B 0}}
$$

Assuming [14] and [15] the system [5]-[11] is written as:

$$
\begin{gathered}
x_{0}=1-\exp \left(-\frac{t}{K_{1}}\right) \\
\dot{x}_{1}=K_{2} \frac{1-p_{1}}{p_{1}}\left(K_{3}-x_{0}\right)\left(\frac{x_{0}}{K_{3}-x_{0}}-\frac{x_{1}}{K_{3}-x_{1}}\right)-N K_{4} \frac{p_{2}}{p_{1}}\left(3 x_{1}-4 x_{2}+x_{3}\right) \\
x_{i}=N^{2} K_{6} \frac{p_{2}^{2}}{p_{1}^{2}}\left(x_{i-1}-2 x_{i}+x_{i+1}\right)-p_{4} x_{i}\left(1-x_{i+N}\right) \quad i=2, \ldots, N
\end{gathered}
$$




$$
\begin{gathered}
\dot{x}_{N+1}=\frac{-N}{2} \frac{p_{2}}{1-p_{1}}\left(x_{N-1}-4 x_{N}+3 x_{N+1}\right)-p_{4} x_{N+1}\left(1-x_{2 N+1}\right) \\
x_{N+2}=-\frac{2}{3} N^{2} K_{6} \frac{p_{2}^{2}}{p_{1}^{2}} p_{3}\left(x_{N+2}-x_{N+3}\right)+p_{5} x_{2}\left(1-x_{N+2}\right) \\
\dot{x}_{N+j}=N^{2} K_{6} \frac{p_{2}^{2}}{p_{1}^{2}} p_{3}\left(x_{N+j-1}-2 x_{N+j}+x_{N+j+1}\right)+p_{5} x_{j}\left(1-x_{N+j}\right) \quad j=3, \ldots, N \\
\dot{x}_{2 N+1}=\frac{-N}{2} \frac{p_{2}}{1-p_{1}} p_{3}\left(x_{2 N-1}-4 x_{2 N}+3 x_{2 N+1}\right)+p_{5} x_{N+1}\left(1-x_{2 N+1}\right) \\
\dot{x}_{2 N+2}=K_{2} \frac{1-p_{1}}{\left(1-p_{1}\right) K_{5}-1}\left(K_{3}-x_{0}\right)\left(\frac{x_{1}}{K_{3}-x_{1}}-\frac{x_{2 N+2}}{K_{3}-x_{2 N+2}}\right)
\end{gathered}
$$

where the dot over the symbols stands for time derivative. The eqs [16] and [23] are the dimensionless ones equivalent to eqs [10] and [11] respectively. The eq. [17] stands for the dimensionless concentration of ' $A$ ' at the reactor eq. [5]. The eq [18] is the discrete version of eq [6] while the eqs [20] and [21] are the discrete version of eq [7]. The dimensionless bulk concentrations are given by eqs [19] and [22] respectively. With this transformation, all the initial conditions of the above system of ODEs are equal to zero. Notice that the original set of ordinary and partial differential equations with mixed boundary conditions is transformed to a system of non-linear first-order ordinary differential equations which can be solved using conventional computing techniques. The constants of the model are:

$$
\begin{array}{ccc}
K_{1}=\frac{V_{B}}{Q} & K_{2}=\frac{Q}{V} & K_{3}=\frac{1}{y_{A 0}} \\
K_{4}=\frac{R T}{2 H_{I O A}} & K_{5}=\frac{V_{R}}{V} & K_{6}=\frac{r_{32}^{2}}{9 D_{A}}
\end{array}
$$

and the parameters are given by:

$$
\begin{gathered}
p_{1}=\varepsilon \quad p_{2}=k_{L} a \quad p_{3}=\xi=\frac{D_{B}}{D_{A}} \\
p_{4}=k_{2} C_{B 0} \quad p_{5}=k_{2} C^{*}
\end{gathered}
$$

Two additional hypotheses have been considered for the definition of the above parameters: i) the diffusion coefficient of $\mathrm{A}$ is known and, ii) the size of the bubbles in 
the BCR is known. While the first of these hypotheses is easily assumed considering that ' $\mathrm{A}$ ' is the ozone which diffusivity is well characterized (Johnson and Davis, 1996), the second one depends on the physical realization of the reactor and its characterization. In a previous work it has been demonstrated that the parameters [25] is the minimal set of parameters allowing the univocal characterization of a reacting gas-liquid system (Navarro-Laboulais et al., 2006). Another significant result of this model is that the Hatta number is inherent to them and it is given by:

$$
H a_{2}^{2}=\frac{9 D_{A}}{r_{32}^{2}}\left(\frac{p_{1}}{p_{2}}\right)^{2} p_{4}
$$

This relation has been found considering the classical definition of Hatta's number but its meaning is different. While the classical definition is done under a steady state framework, the eq. [26] refers to the value of this modulus for $t \rightarrow 0$ in an unsteady state situation. This parameter can be understood as the initial Hatta number which can lead to the estimation of an initial enhancement factor using some eq. like [2] or [3].

\section{3.- The Optimization Procedure}

Once the model has been derived, the parameters defined by eqs. [25] must be obtained fitting the model to the experimental data. Let us consider that we want to obtain the set of parameters that minimizes the sum of squares of the residuals, the difference between the experimental and the expected values of the concentrations. In this case, the optimum parameter set in a least-squares sense is such that minimizes the objective function defined as:

$$
\Phi_{L S}(\mathbf{p})=\sum_{k=1}^{M}\left(\hat{\mathbf{x}}_{k}-\mathbf{x}\left(t_{k} ; \mathbf{p}\right)\right)^{T} \mathbf{Q}_{k}\left(\hat{\mathbf{x}}_{k}-\mathbf{x}\left(t_{k} ; \mathbf{p}\right)\right)
$$

where $\boldsymbol{Q}_{k}$ are the weighting matrices and all the bold symbols refer to vector or matrix magnitudes. $\mathbf{p}$ is the parameter set of the model i.e. eqs. [25], $\mathrm{M}$ is the number of experimental values for each observable variable, $\hat{\mathbf{x}}_{k}$ is the vector of experimental observations of size $(v \times 1)$ and $\mathbf{x}\left(t_{\mathrm{k}} ; \mathbf{p}\right)$ the vector of expected concentrations of the same size $(v \times 1)$ both evaluated at $t_{\mathrm{k}}$, where $v$ is the number of observable variables. The necessary condition to minimize [27] against $\mathbf{p}$ is given by:

$$
\frac{\partial \Phi_{L S}(\mathbf{p})}{\partial \mathbf{p}}=\sum_{k=1}^{M}\left[\frac{\partial \mathbf{x}^{T}\left(t_{k} ; \mathbf{p}\right)}{\partial \mathbf{p}} \mathbf{Q}_{k}\left(\widehat{\mathbf{x}}_{k}-\mathbf{x}\left(t_{k} ; \mathbf{p}\right)\right)+\left(\widehat{\mathbf{x}}_{k}-\mathbf{x}\left(t_{k} ; \mathbf{p}\right)\right)^{T} \mathbf{Q}_{k} \frac{\partial \mathbf{x}\left(t_{k} ; \mathbf{p}\right)}{\partial \mathbf{p}}\right]=0
$$


Linearizing the theoretical concentration $\mathbf{x}\left(t_{\mathrm{k}} ; \mathbf{p}\right)$ around some initial value $\mathbf{p}_{0}$ and solving the linear set of equations [29], it is possible the evaluation of the direction, $\Delta \mathbf{p}$, towards which the objective function minimizes:

$$
\left[\sum_{k=1}^{M} \mathbf{S}_{k}^{T} \mathbf{Q}_{k} \mathbf{S}_{k}\right] \Delta \mathbf{p}=\sum_{k=1}^{M} \mathbf{S}_{k}^{T} \mathbf{Q}_{k}\left(\hat{\mathbf{x}}_{k}-\mathbf{x}\left(t_{k} ; \mathbf{p}_{0}\right)\right)
$$

where the sensitivity matrix, $\mathbf{S}_{k}$, for our problem is defined as:

$$
\mathbf{S}_{k}=\mathbf{S}\left(\mathbf{x}\left(t_{k} ; \mathbf{p}_{0}\right)\right)=\left(\frac{\partial \mathbf{x}^{T}}{\partial \mathbf{p}}\right)_{\mathbf{p}_{0}}^{T}=\left(\begin{array}{ccccc}
\frac{\partial x_{1}}{\partial p_{1}} & \frac{\partial x_{1}}{\partial p_{2}} & \frac{\partial x_{1}}{\partial p_{3}} & \cdots & \frac{\partial x_{1}}{\partial p_{5}} \\
\frac{\partial x_{2}}{\partial p_{1}} & \frac{\partial x_{2}}{\partial p_{2}} & \frac{\partial x_{2}}{\partial p_{3}} & \cdots & \frac{\partial x_{2}}{\partial p_{5}} \\
\vdots & \vdots & \vdots & \ddots & \vdots \\
\frac{\partial x_{2 N+2}}{\partial p_{1}} & \frac{\partial x_{2 N+2}}{\partial p_{2}} & \frac{\partial x_{2 N+2}}{\partial p_{3}} & \cdots & \frac{\partial x_{2 N+2}}{\partial p_{5}}
\end{array}\right)
$$

One of the difficulties of the method [27]-[29] lies with the estimation of $\mathbf{S}_{k}$. There are different methods for its determination: i) analytically which can be tedious and a source of errors for big and complex systems of ODE's; ii) numerically, which round-off errors can lead to convergence problems. In our case, a Mathematica ${ }^{\circledR}$ code was written for automatic derivation of matrix elements of $\mathbf{S}_{k}$ and numerical resolution jointly with the model equations [16]-[23].

The success of the convergence of the optimization algorithm by least-squares minimization depends on several factors: i) the value of the initial parameters for the iteration algorithm; ii) the model structure, i.e. how the parameters of the model are interrelated; and iii) the relative sensitivity of each parameter on every observable macroscopic magnitude. Related to the first factor, there are not general rules to derive a set of reliable initial guesses for the optimization algorithm and depends mainly on the knowledge and practice of the experimenter. However, in our case, a novel methodology based on Artificial Neural Networks (ANN) has been applied to estimate adequate parameters values for using as initial guesses for the optimization algorithm. In this procedure ANNs are trained with information of the mathematical model in order to identify the parameter values in function of the temporal evolution of the observable variables. The algorithm was programmed in Matlab v7.11 (R2010b) using Neural Network Toolbox v7.0 and it is based on the following steps:

1- Data generation: Using the mathematical model, simulations are performed varying parameters, $\mathbf{p}$, and considering the operational conditions. From each simulation we obtain the theoretical temporal evolution of the observable variables. 
2- Geometric Characterization. The temporal evolution of each observable variable is geometrically characterized obtaining the reference times for some relative concentrations $(10,25,50,75$ and $90 \%$ for example), as it is shown in Fig. 2. The reference times, $\mathbf{T}$, are related to $\mathbf{p}$ for every simulation. For calculation purposes the reference times considered were $5,10,15,20,25,50$, $75,80,85,90,95$ and $98 \%$. With these relative concentrations we ensure that we recover all the geometrical information of the curve.

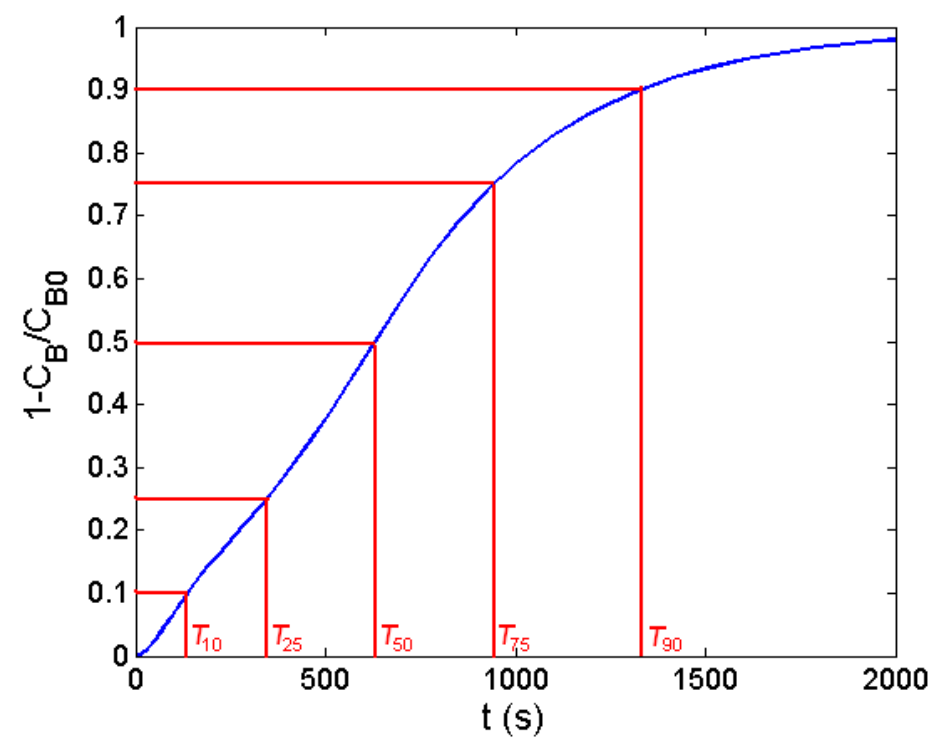

Fig. 2. Geometric characterization on curves of normalized concentrations of species. The reference times for relative concentrations of 10, 25, 50, 75 and $90 \%$ are selected in this example.

3- ANN Construction, Training and Validation: The pair of T-p data is used to train a multilayer neural network, using the reference times as the input and the parameters as the outputs/targets. The structure of ANN is optimized for each case increasing the number of hidden neurons until the performance of network is not improved. To validate the ANN, two performance statistical criteria are used: the correlation coefficient and the squared mean error between the parameters of simulations and those calculated by the ANN.

4- ANNs Usage. Finally, to use the trained and validated network, the reference times of experimental data are obtained by the same way that for simulations and these values are introduced in the network for calculating the initial guesses for Gauss-Newton algorithm. 
Additionally, the ANNs can be related and used for the analysis of the model structure and its parameter sensitivity. For example, the parameters defined in the previous section, i.e. eqs. [25], are derived from the structural identifiability analysis of a transfer-reaction gas-liquid model (Navarro-Laboulais et al., 2006). Furthermore, the parameter sensitivity analysis of the model (Navarro-Laboulais et al., 2008; Cardona et al., 2010) allows the identification of the insensitive parameters, i.e. the parameters which do not affect the state variables behaviour when they are modified. From the sensitivity analysis it has been demonstrated that for slow and fast kinetic regimes, the model is insensitive to parameters $p_{1}$ and $p_{3}$, which implies that these parameters cannot be obtained by fitting the model to the concentration-time data and they must be determined by alternative methods. Carrying out the sensitivity analysis using the ANNs, the results agree with those obtained by standard sensitivity analysis methods (Navarro-Laboulais et al., 2008; Cardona et al., 2010). The results of this analysis conclude that the relative sensitivity of the parameters are $k_{L} a>p_{4} \sim p_{5}>\varepsilon>>\xi$. As an advantage, ANN study supplies information for combinations of parameters together, and conclude that only $k_{L} a$ with $p_{4}$ or $k_{L} a$ with $p_{5}$ can be estimated together. Furthermore, this study concludes that to estimate $p_{4}$ and $p_{5}$ the evolution of substrate must be known; and to estimate $k_{L} a$ the concentration of ozone in the gas or in the liquid phase must be known.

The optimization process reduces then to the determination of parameters $p_{2}, p_{4}$ and $p_{5}$, otherwise, the determination of $k_{L} a, k_{2} C_{\mathrm{B} 0}$ and $k_{2} C^{*}$ respectively. The existence of these two last parameters points out that a good experimental design for an accurate determination of the kinetic rate constant is to run at least two experimental series, one of them changing the initial dye concentration, $C_{\mathrm{B} 0}$, and the other one, changing the inlet ozone gas concentration which modifies the ozone saturation concentration, $C^{*}$.

\section{4.- Experimental Apparatus and Materials}

The reactor designed for the study of the ozonation processes is shown on Fig. 1. It consists of three parts: i) the gas mixing chamber; ii) the gas distributor or gas sparger; and iii) the reactor body comprising the upper gas chamber. The gas mixing chamber has a volume of $2.55 \mathrm{~L}$ and its function is to equalize the gas composition and the pressure at the entrance of each capillary. This chamber avoids the nonuniformities in flow and composition during the ozone injection. The experiments consist in a sudden injection of ozone in the reacting media without changing the total gas flow rate in the reactor. The gas distributor is formed by 61 capillaries uniformly distributed on the reactor surface separated $2.1 \mathrm{~cm}$ between them. The capillaries are $14 \mathrm{~cm}$ length with an inner diameter of $0.4 \mathrm{~mm}$. With this configuration and the operating conditions applied, no bubble coalescence has been observed. The study of the bubble formation when some gas flows through a submerged rigid orifice has been carried out both experimental (Jamialahmadi et al. 2001) and theoretically (Das and 
Das, 2009; Gerlach et al. 2007). The generalized expression given in those works for the bubble volume calculation has been used here to estimate the Sauter's bubble radius needed for the mathematical unstationary model. Following the authors aforementioned:

$$
\frac{v_{B}}{R_{0}^{3}}=\frac{4 \pi}{3}\left[\frac{1.119}{B o^{1.08}}+1.406 \frac{F r^{0.36}}{G a^{0.39}}+0.469 F r^{0.51}\right]
$$

where $v_{\mathrm{B}}$ is the bubble volume, $R_{0}$ the orifice radius, and $B o, F r$ and $G a$, are the Bond, Froude and Galileo dimensionless numbers respectively. These numbers are function of water properties as density, $\rho_{L}$, viscosity, $\mu$, and surface tension, $\sigma$, (IAPWS, 1994; IAPWS, 2008; Tanaka et al., 2001):

$$
B o=\frac{\rho_{L} \cdot g \cdot R_{o}^{2}}{\sigma} \quad ; \quad F r=\frac{q}{R_{o}^{5} \cdot g} \quad ; \quad G a=\frac{\rho_{L}^{2} \cdot g \cdot R_{o}^{3}}{\mu^{2}}
$$

where $q$ is the gas flow rate through one single capillary.

The total geometrical volume of the reactor, $V_{\mathrm{R}}$, is $10.32 \mathrm{~L}$. The working liquid volume, $V$, has been fixed to $9.0 \mathrm{~L}$ for each experiment in order to prevent the reactor overflow by water expansion.

A scheme of the instrumentation fitted to the ozonation reactor is shown in Fig. 3. The ozone generator used in the experiments is an Anseros COM-AD-04 where the ozone production is changed modifying the pulse frequency in the discharge lamps. The ozonator is fed with pure oxygen (Carburos Metálicos) at constant pressure of 0.9 bar. Under these circumstances, the maximum ozone concentration measured was around $80 \mathrm{~g} \mathrm{Nm}^{-3}$ for an oxygen flow rate of $2.0 \mathrm{~L} \mathrm{~min}^{-1}$. 


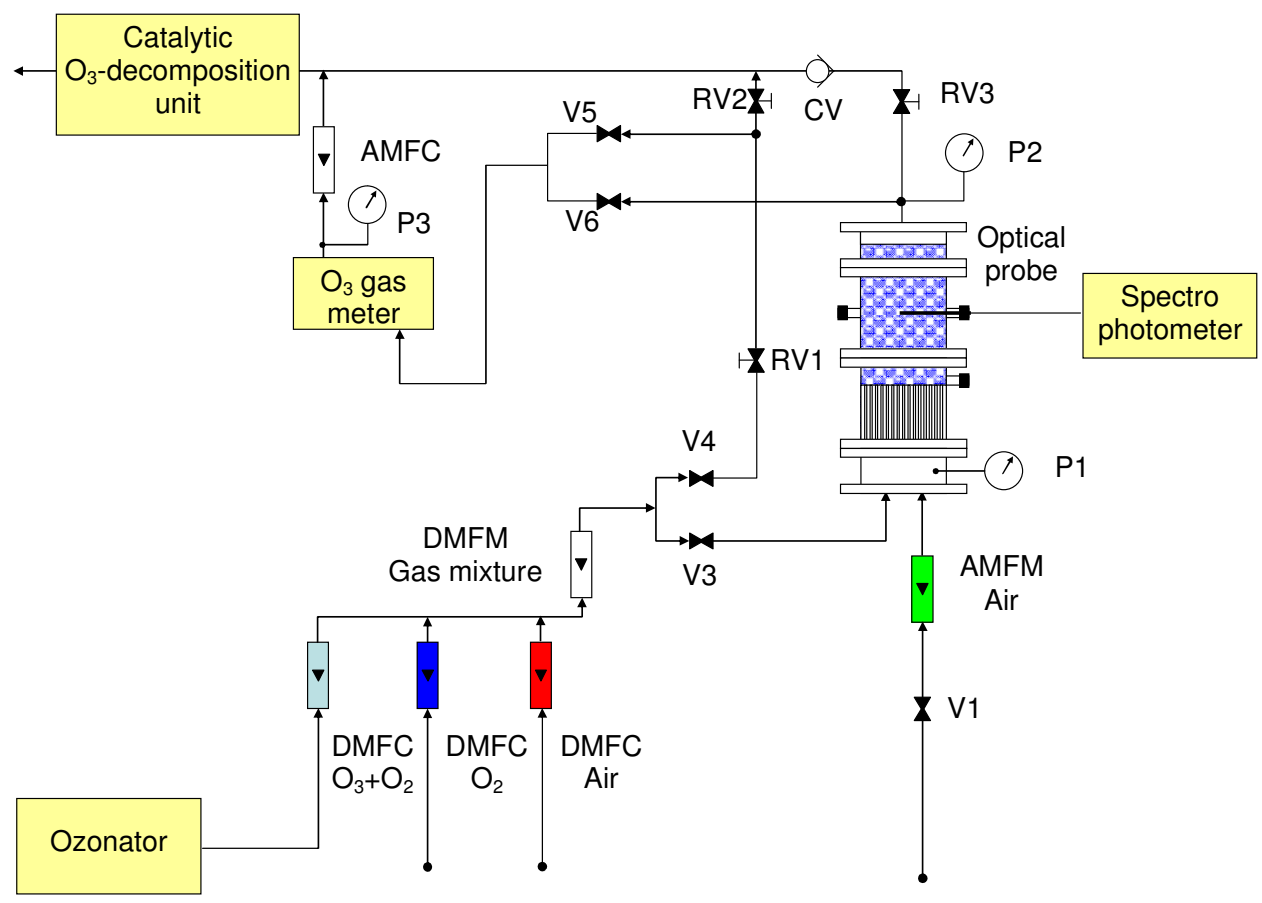

Fig. 3. Diagram of the experimental set-up. The digital mass-flow controllers and meter (DMFC and DMFM) are connected to a computer using a RS485 protocol. The analogue mass-flow controller and meter (AMFC and AMFM) are connected to the analogue outputs or inputs of the data acquisition card. The solenoid valves (V1 to V6) are controlled by the digital input/output of the same card. The pressures are measured at the gas mixing chamber (P1), the reactor head (P2) and at the ozone-meter line (P3)

An analogue mass-flow meter (M+W Instrumentation $\mathrm{GmbH}$, model D6210; see AMFM Air in Fig. 3) was used to measure the air flow rate used to degas the reactor. This flow was fixed by hand with a manual regulation valve (not shown in the diagram). The gas mixture used in the reactions was set using three digital mass-flow controllers (Bronkhorst, Mod. EL-Flow F201CV; see DMFC $\mathrm{O}_{3}+\mathrm{O}_{2}, \mathrm{O}_{2}$, Air in Fig. 3) and the mixture was measured with a digital mass-flow meter (Bronkhorst, Mod. ELFlow F111B; see DMFM Gas Mixture in Fig. 3). These digital instruments were connected through a RS485 bus, and the communication with them is done using a Dynamic Data Exchange (DDE) server. Additionally, the RS485 is connected to the computer via RS485-to-USB converter (National Instruments, NI USB-485) giving the maximum connectivity of the instruments with the minimum computer resources.

The gas mixture is then sent to the reactor gas-mixing chamber or to the venting point of the system using several two-port solenoid valves (SMC, VDW Series; see V1-V6 in Fig. 3). These valves are controlled with the digital port of the 
data acquisition card using a self-made interface which converts the state of each digital gate to a $0-24 \mathrm{~V}$ signal which commands the solenoid valve. With the combination of the valves shown in Fig. 3 it is possible to measure the ozone gas not only at the output of the reactor, but also at the input.

The ozone in the gas phase has been measured using an UV-absorption $\mathrm{O}_{3}-$ meter at $254 \mathrm{~nm}$ (Anseros, Ozomat GMRTI) which is able to measure up to $200 \mathrm{~g} \mathrm{~m}^{-3}$. It is important to consider here the flow rate and the pressure at which the measure is done, P3. The gas flow rate through the measuring cell in the $\mathrm{O}_{3}$ meter must be constant because if this value changes, different delay times should be applied in the kinetic curves. Then, an analogue mass flow controller (AMFC, Aalborg, Mod. GFC17) has been linked to the Ozomat meter, fixing the flow rate to $0.3 \mathrm{~L} \mathrm{~min}^{-1}$. The ozone-gas concentration measure depends on the pressure and the constancy of this property cannot be ensured in all the installation. In order to avoid this problem, instead of the measurement of the ozone in the units given by the instrument, i.e. $\mathrm{g} \mathrm{m}^{-3}$, it is better to change the units to mole fraction. This unit conversion has the advantage that the ozone mole fraction is insensitive to pressure changes along the reactor. Additionally, the gas pressure is measured in other two critical points in the system, the pressure at the reactor head (see P2 in Fig. 3) and in the gas mixing chamber (P1 in Fig. 3). All the pressure transmitters are from Druck Limited (Mod PTX 1400) and give a 4-20 mA output proportional to pressure gauge.

The ozonation reactor was fitted to a UV-Vis spectrophotometer to measure the abatement of the reacting substances in the reactor. An Unicam Helios-Gamma spectrophotometer fitted with a Hellma Ultra-Mini Immersion Probe (Mod 661.622) has been used in the experiments. The spectrophotometer data is acquired with the serial RS232 port of the computer.

Finally, all the analogue inputs and outputs of the instruments are linked to a computer using a data acquisition card (Advantech, PCI1710-HG). The card has 8 analogue inputs configured in differential mode and 16 digital inputs/outputs which are used to control the solenoid valves states. The software controlling all the process was developed using LabView 8.20 (National Instruments) which manages properly all the devices linked to the computer.

The dyes used in the kinetic experiments were the Acid Red 27 (AR27, CAS 915-67-3, $\mathrm{Mr}=604.47 \mathrm{~g} \mathrm{~mol}^{-1}$, by Sigma-Aldrich ref A1016), the Acid Orange 7 (AO7, CAS 633-96-3, $\mathrm{Mr}=350.32$, by Fluka ref 69143) and the Acid Blue 129 (AB129, CAS 6397-02-0, $\mathrm{Mr}=460.48$, by Sigma-Aldrich ref 306495). The concentrations of the dyes were determined through the absorbance measured at 520, 485 and $591 \mathrm{~nm}$ respectively. All the solutions were set to $\mathrm{pH}=2$ with $\mathrm{HClO}_{4}$ (Panreac, PA, ref. 132175) and the ozone radical reactions were blocked adding 0.01 M of tert-Butanol (2-Methyl-2-Propanol, Panreac PS, ref. 161903). 


\section{5.- Experimental Results and Discussion}

Before to describe the kinetic experiments, let us consider the physical characterization of the gas-liquid reactor. The measurement of the concentration of ozone in the gas phase is of great importance for kinetic experiments whether we want to determine the experimental enhancement factors or if we want to obtain the kinetic information from the ozone-gas time course. In the precedent section it has been shown that this magnitude is measured with an $\mathrm{O}_{3}$-meter based on the UV-absorption of this gas at $254 \mathrm{~nm}$. In order to check the proper operation and error sources of the instrument, a series of absorption experiments in pure water were done (results not shown here). Because absorption experiments are unstationary we expect that the final measured ozone concentration at the exit of the reactor is the same that in the input one. Our experimental set-up allows the measurement of the input ozone concentration by by-passing out the ozone in the reactor (consider in Fig. 3: V3, V6: closed and V4, V5: open). Along the experiment, the by-pass is closed and the ozone is continuously measured at the reactor off-gas (in Fig. 3: V3, V6: open and V4, V5: closed). In the Fig. 4a the initial (by-pass) and final (reactor) ozone-gas concentrations from the absorption experiments are shown. We observe a systematic discrepancy between these two magnitudes which origin is the pressure changes in the gas pipes due to the difference in the head losses at the by-pass or the reactor. To correct these errors, a pressure transmitter was installed at the $\mathrm{O}_{3}$-meter output (see P3 in Fig. 3) to measure the absolute pressure at which the ozone absorbance is read. Knowing both concentrations and pressures the ozone mole fraction can be estimated in any point of the system. Moreover, this magnitude is insensitive to pressure changes and thus, is the most appropriate way to evaluate the observable state variables $x_{0}, x_{1}$ or $x_{2 \mathrm{~N}+2}$, i.e. eqs. [16], [17] and [23]. The Fig. 4b shows the initial (by-pass) and final (reactor) ozone mole fractions from absorption experiments once the pressure in each line is corrected. Notice that in this case there is a good agreement between both magnitudes, concluding that the mole fraction is the adequate magnitude to express the concentration of the ozone in the gas phase.
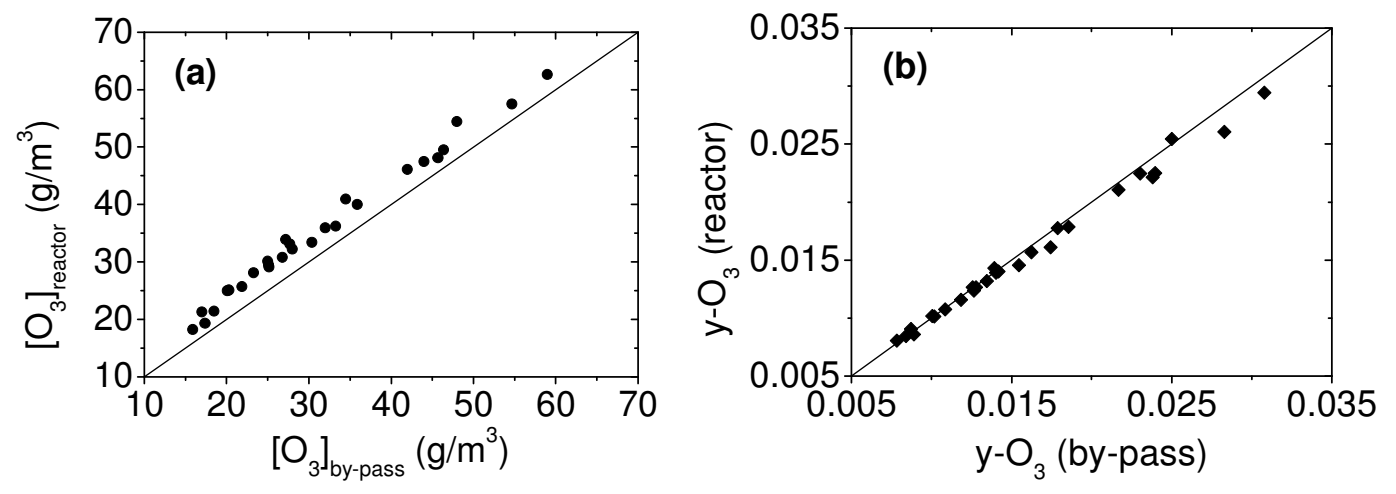
Fig. 4. Systematic errors correction in ozone gas-concentration measurements. (a) Direct ozone measurements; initial ozone (by-pass) vs. final ozone concentration (reactor); the direct reading of the $\mathrm{O}_{3}$-meter is given in $\mathrm{g}-\mathrm{O}_{3} / \mathrm{m}^{3}$. The line is of unit slope showing a systematic error in the gas measurement due to pressure discrepancy. (b) Ozone mole fraction correction; initial ozone concentration (by-pass) vs final ozone concentration (reactor).

In the section 3 and in precedent works (S.C. Cardona et al., 2010) it has been pointed out that the gas hold up cannot be measured by kinetic techniques, and then, alternative experiments must be done to measure this property. The gas hold-up, $\mathcal{E}$, has been estimated independently by a manometric method and a volume displacement method. In the manometric method, the hydrostatic pressure of the water column and the hydrostatic pressure of the air-water column are related through the gas hold-up by:

$$
\varepsilon=1-\frac{P_{G L}}{P_{W}}
$$

where $P_{W}$ is the hydrostatic pressure of the water column and $P_{G L}$ is the hydrostatic pressure measured with the air-water mixture. On the other hand, the gas hold-up could be evaluated also measuring the mass of water displaced when the air flows through a water column which is initially at rest. In this case we have:

$$
\mathcal{E}=\frac{M_{\text {disp }}}{M_{W c o l}}
$$

where $M_{\text {disp }}$ is the mass of water displaced by the gas flow and $M_{W c o l}$ the initial mass of the water column. In the determination of $\varepsilon$ by both methodologies, manometric or volume displacement, the reactor must have a weir in its upper side in order to ensure a constant fluid (gas or liquid) volume. The results are plotted on Fig. 5a showing a very good agreement between both methodologies. For the manometric method, two pressure transmitters with different full-scale range (250 and 100 mbar) were used for $\varepsilon$ determination in order to check the accuracy of the method. These two values agree with the volume displacement method concluding that this last method could be the most appropriate method for the determination of $\varepsilon$ in small BCRs when the hydrostatic pressure of the bubble column could not be measured accurately.

Finally, although the numerical method proposed in this paper allows the estimation of the mass transfer coefficient together with the kinetic rate constant, the usage of the optimization algorithm together the sensitivity analysis of the model have 
shown that there is a strong correlation between these two parameters. Moreover, this correlation is negative and thus implies that if one of the parameters has some effect on state variables of the system when it is increased, the opposite effect can be achieved decreasing the other correlated parameter. The existence of correlations between the parameters of a model increases significantly the confidence interval of the parameters, jeopardizing all the methodology. To avoid this problem, the gasliquid mass transfer coefficient of our reactor has been determined with oxygen absorption experiments. Initially, the water was degassed with $\mathrm{N}_{2}$ and then oxygen concentration evolution is measured bubbling air in the reactor. The mass transfer coefficient for the oxygen at different air flow rates is shown on Fig. 5b. The mass transfer coefficient for the ozone has been estimated considering that:

$$
\frac{\left.k_{L} a\right|_{O_{3}}}{\left.k_{L} a\right|_{O_{2}}}=\left(\frac{D_{O_{3}}}{D_{O_{2}}}\right)^{d}
$$

where $k_{L} a l_{j}$ is the mass transfer coefficient for the gas ' $j$ ', $D_{O_{3}}$ and $D_{O_{2}}$ the diffusivities of the ozone and oxygen, respectively, and the exponent $d$ is related with the gas-liquid model used for the interface description. Thus, $d=1$ for the stagnant film theory, $d=1 / 2$ for surface renewal theory and $1 / 2 \leq d \leq 1$ for eddy-diffusion theory. For consistency with our model we have considered $d=1$. The ozone diffusivity has been calculated following to Johnson and Davis (1996) and the oxygen diffusivity to Ferrell and Himmelblau (1967).
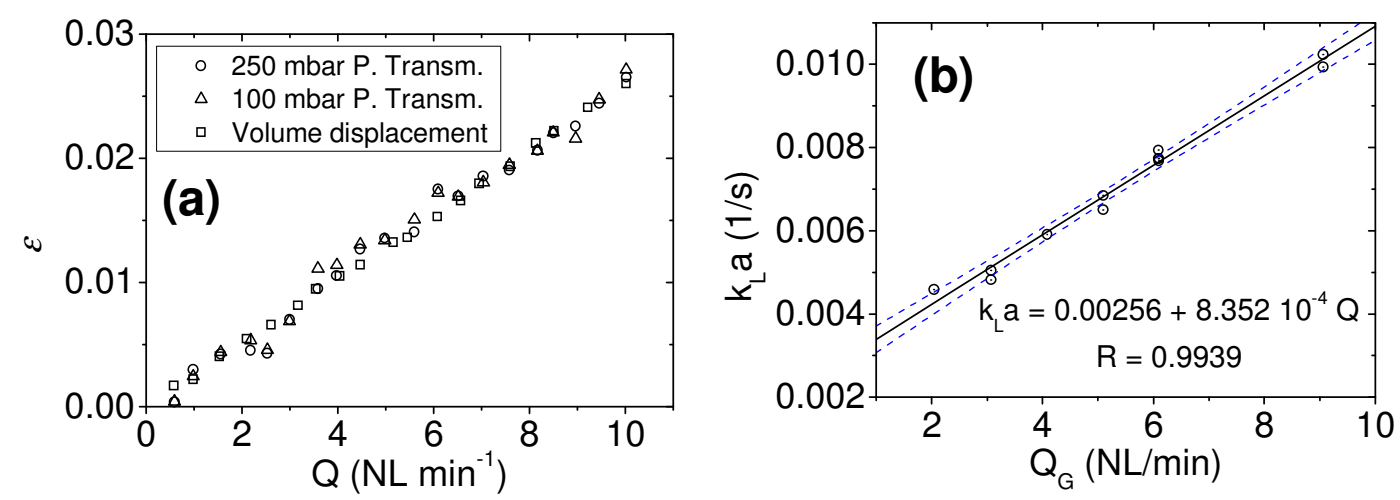

Fig. 5. Physical characterization of the gas-liquid reactor. (a) Gas hold-up determined following the manometric and volume displacement methods. The linear relationship is typical for homogeneous hydrodynamic regime. (b) Mass transfer coefficient obtained from oxygen absorption experiments. The ozone mass transfer coefficients are derived from the line together the eq. [35]. 
For the determination of the kinetic rate constants, two series of experiments for each azo-dye have been designed. Because the two kinetic parameters to be determined in the model are $p_{4}=k_{2} C_{B 0}$ and $p_{5}=k_{2} C^{*}$ one of the series consists to maintain the inlet ozone concentration constant and to change the initial dye concentration, while in the second series, the initial dye concentration is constant and the input ozone concentration changes. Therefore, plotting the estimated value of $p_{4}$ and $p_{5}$ against $C_{B 0}$ and $C^{*}$ respectively gives the absolute rate constant $k_{2}$. In the following the kinetic experiments with the AR27 are discussed with some detail and since the experiments for the AB129 and AO7 are very similar, just the final kinetic rate constants will be shown.

The absorbance signal measured must be filtered because there is a nongaussian noise perturbing the true signal. In the Fig. 6a it is shown a typical absorbance trace for the AR27 ozonation. The true absorbance points were placed on the lower envelope of the signal and there is noise always above the signal. If a classical filtering technique such as moving average is used, the filtered signal has a bias added to the true absorbance (see Fig 6b). Therefore, in our case we have filtered the absorbance signal using the methodology proposed by Gupta et al. (2000). This is an iterative algorithm which implements the Butterworth filter that is applied to the raw signal at every iteration and only the points which are above the original ones, are removed from the original set. With this method the points which belong to the signal envelope are not modified. The algorithm is stopped when the sum of squares of the difference between the raw signal and filtered signal is below a given tolerance $\left(10^{-6}\right.$ in present work). For more details, we refer the reader to the original paper (Gupta et al., 2000).
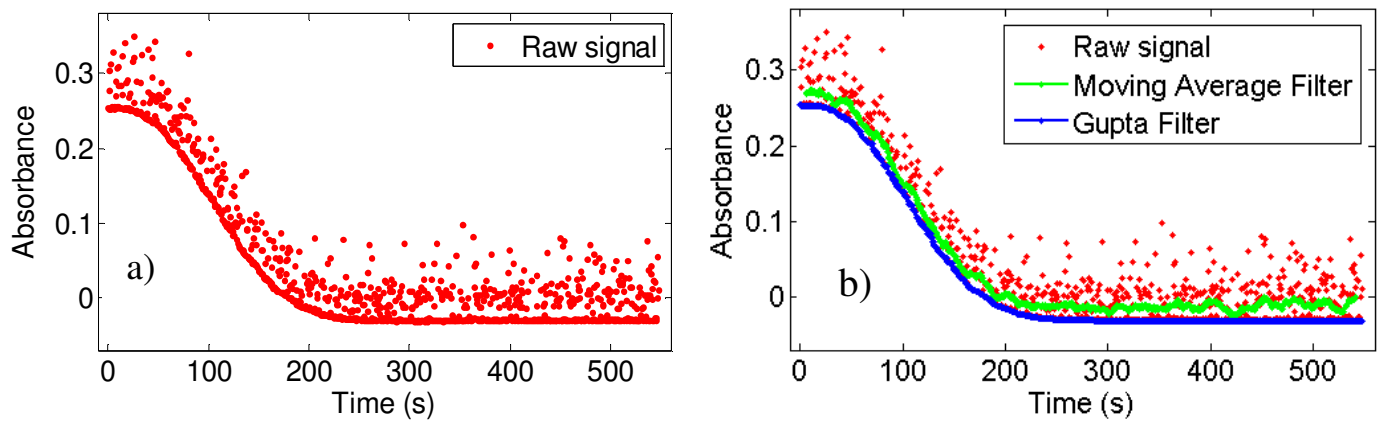

Fig. 6. Absorbance at $520 \mathrm{~nm}$ measured during ozonation of AR27. (a) Experimental raw data with non-gaussian noise. (b) Filtered data using the moving average (order 25) and the Gupta method.

The Fig 7 shows the AR27 conversion (a) and the dimensionless ozone gas concentration (b) for the ozonation experiments at constant ozone input concentration. In this case, the $\mathrm{O}_{3}$-gas concentration is $\sim 14 \mathrm{~g} \mathrm{~m}^{-3}$ in all experiments and the initial 
dye concentration is indicated on the curves. This gas concentration leads to $C^{*} \cong 66.9$ $\mu \mathrm{M}$ which implies a great excess of ozone respect to the dye. All experiments were done in a $0.01 \mathrm{M} \mathrm{HClO}_{4}+0.01 \mathrm{M} \mathrm{t}-\mathrm{BuOH}$ medium to avoid the ozone selfdecomposition reactions and the ozone radical reaction mechanism. The AR27 concentration was followed measuring its absorbance at $520 \mathrm{~nm}$. The Fig. 7a shows that when the initial dye concentration increases the reaction completion is achieved at longer times. On the other hand, the Fig. $7 \mathrm{~b}$ shows the dimensionless ozone concentrations for the same series of experiments. We notice that there is not any feature in the curves which could be associated to the chemical reaction. In fact, the shape of the curves is very similar to absorption experiments and independent of the dye concentration because the great excess of ozone. Additionally, the dilution and integration effect of the reactor head chamber can also be in the origin of this information loss. The optimization procedure used for the kinetic rate constant determination can in theory fit the model to the data using only the data shown in Fig. $7 \mathrm{a}$, only the data in Fig. $7 \mathrm{~b}$ or both set of experimental data. When exclusively the gas phase data are used (Fig. 7b), the optimization algorithm obtains parameter values without physical sense because this lack of relevant kinetic information, as was demonstrated in the parameter sensitivity analysis of the model (Navarro-Laboulais et al., 2008; Cardona et al., 2010). Otherwise, when the data set used for fitting the model is the dye concentration (Fig. 7a) or both the ozone gas and dye concentration (Figs. $7 \mathrm{a}$ and $7 \mathrm{~b}$ ), the algorithm converges adequately. It should be noted that in gas phase exists a little difference between experimental and fitted data due to reactions of ozone with by-products. Therefore, other reaction schemes must be considered in the mathematical model, but also the evolution of by-products should be measured in order to get an adequate characterization.
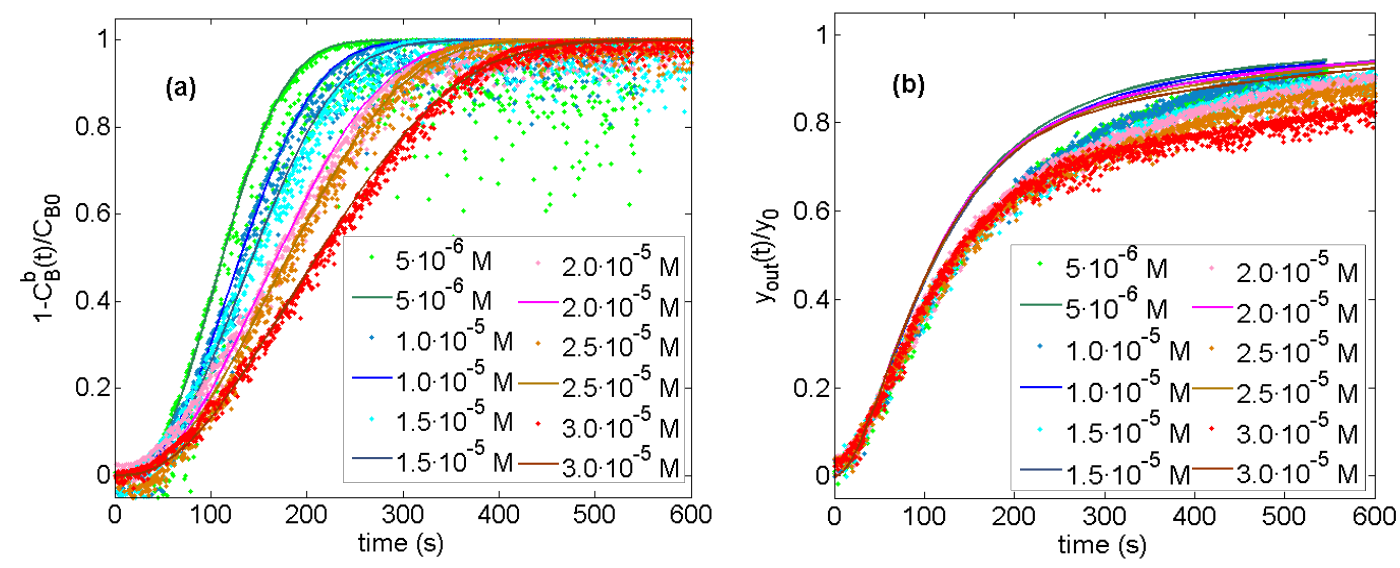

Fig. 7. Acid Red 27 ozonation experiments at constant inlet ozone-gas concentration. (a) The AR27 conversion plotted is identified with the state variable $x_{2 \mathrm{~N}+1}$ in eq. [22]. The initial dye concentration is indicated on graph legends. The AR27 absorbance was measured at $520 \mathrm{~nm}$. (b) Ozone 
gas evolution for different initial dye concentration (state variable $x_{2 \mathrm{~N}+2}$ in eq. [23]). The conditions of the experiments were $\left[\mathrm{O}_{3}\right]_{\mathrm{g}} \sim 14 \mathrm{~g} \mathrm{~m}^{-3}, C^{*} \cong$ $66.9 \mu \mathrm{M}, \mathrm{T}=21.2{ }^{\circ} \mathrm{C},\left[\mathrm{HClO}_{4}\right]=0.01 \mathrm{M},[\mathrm{t}-\mathrm{BuOH}]=0.01 \mathrm{M}$. The lines are the best fit to the ODE system [16]-[23].
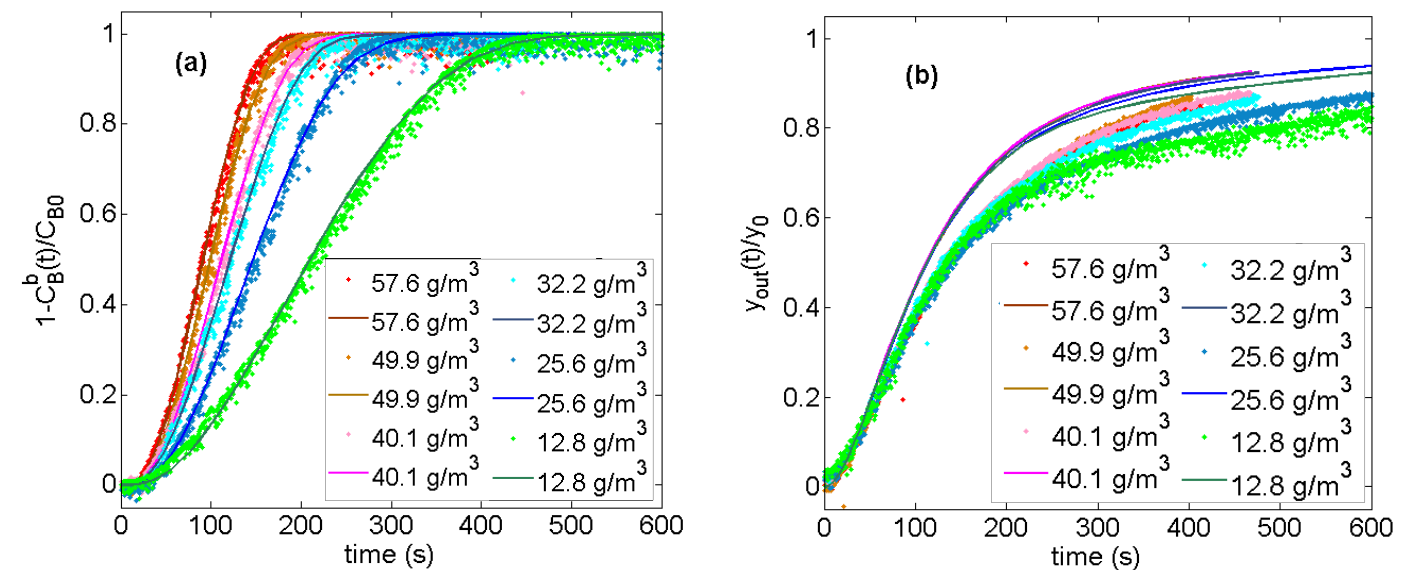

Fig. 8. Acid Red 27 conversion for ozonation experiments at constant initial dye concentration and different gas input concentration (see legends). (a). The AR27 absorbance was measured at $520 \mathrm{~nm}$. (b) Ozone gas evolution for different inlet ozone gas concentrations. The conditions of the experiments were $[\mathrm{AR} 27]_{0}=C_{B 0}=30 \mu \mathrm{M}, \mathrm{T}=21.2^{\circ} \mathrm{C},\left[\mathrm{HClO}_{4}\right]=$ $0.01 \mathrm{M},[\mathrm{t}-\mathrm{BuOH}]=0.01 \mathrm{M}$. The lines are the best fit to the ODE system [16]-[23].

The Figs $8 \mathrm{a}$ and $8 \mathrm{~b}$ show the response of the AR27 conversion and ozone gas concentration in the second series of experiments, where the initial AR27 concentration remains constant and the ozone-gas inlet concentration changes in each run. The initial dye concentration for this series was fixed to $30 \mu \mathrm{M}$ while the saturation ozone concentration ranged from 71 to $309 \mu \mathrm{M}$. We observe that when the inlet ozone concentration increases the reaction evolves faster. These data have been fitted with ANN's and the results are shown in Table I. The structure of the ANNs was different for each case but with the following general neurone structure: i) 12 neurones in the input layer; ii) first hidden layer with 2-4 neurones; iii) a potential second hidden layer with few neurones; and iv) an output layer with one neurone. With this structure we ensure that the convergence criteria described in Section 3 are achieved. Once the parameter $p_{5}$ is determined by the ANN, this value is used as initial value for the Gauss-Newton (GN) algorithm. As it is shown in Table I, because the $p_{5}$ values estimated by the ANNs are very near to the optimum, then the Gauss-Newton algorithm converges quickly. The advantage of the optimal value of $p_{5}$ derived from the GN is that it is possible to provide a confidence interval for this parameter and then, the error estimation for the kinetic rate constants. 
Table I. Calculated values for parameter $p_{5}$ using artificial neural networks (ANN) or Gauss-Newton algorithm (GN) for experiments of Fig. 8

\begin{tabular}{cccc}
\hline Dye & $C^{*}(\mu \mathrm{M})$ & $p_{5}(\mathrm{ANN})\left[\mathrm{s}^{-1}\right]$ & $p_{5}(\mathrm{GN})\left[\mathrm{s}^{-1}\right]$ \\
\hline & 383 & 0.029 & $0.0210 \pm 0.0003$ \\
Acid Blue & 295 & 0.016 & $0.0143 \pm 0.0001$ \\
129 & 257 & 0.017 & $0.0117 \pm 0.0002$ \\
& 205 & 0.015 & $0.00806 \pm 0.00007$ \\
& 118 & 0.010 & $0.00535 \pm 0.00005$ \\
& 58 & 0.002 & $0.00238 \pm 0.00002$ \\
\hline & 280 & 0.107 & $0.135 \pm 0.002$ \\
Acid & 245 & 0.156 & $0.1560 \pm 0.0001$ \\
Orange 7 & 196 & 0.250 & $0.180 \pm 0.001$ \\
& 137 & 0.078 & $0.062 \pm 0.001$ \\
& 72 & 0.029 & $0.0364 \pm 0.0007$ \\
\hline & 309 & 0.391 & $0.541 \pm 0.002$ \\
Acid Red & 261 & 0.326 & $0.433 \pm 0.002$ \\
27 & 206 & 0.364 & $0.319 \pm 0.001$ \\
& 168 & 0.225 & $0.2882 \pm 0.0009$ \\
& 145 & 0.120 & $0.1474 \pm 0.0004$ \\
& 71 & 0.077 & $0.0768 \pm 0.0002$ \\
\hline
\end{tabular}

Finally, let us define the $t_{90}$ as the time needed to attain the $90 \%$ of the dye conversion. The Fig. 9 shows the $t_{90}$ vs $C^{*}$ for all the dyes at initial concentrations of 30.0, 65.9 and $40.0 \mu \mathrm{M}$ for the AR27, AB129 and AO7 respectively. We observe a great difference between the $t_{90}$ of the AB129 and its value for the other two substances. Thus, we confirm with this measure that the AB129 is the substance that reacts slower with the ozone. However, the reaction rates for the AR27 and the AO7 are very similar and nothing about the kinetic rate constant can be said from this plot, except that maybe the reaction with the AR27 is slightly faster than the AO7. Although the plot of $t_{90}$ vs $C^{*}$ can give us some qualitative information about the relative reaction rates, no quantitative one can be derived. 


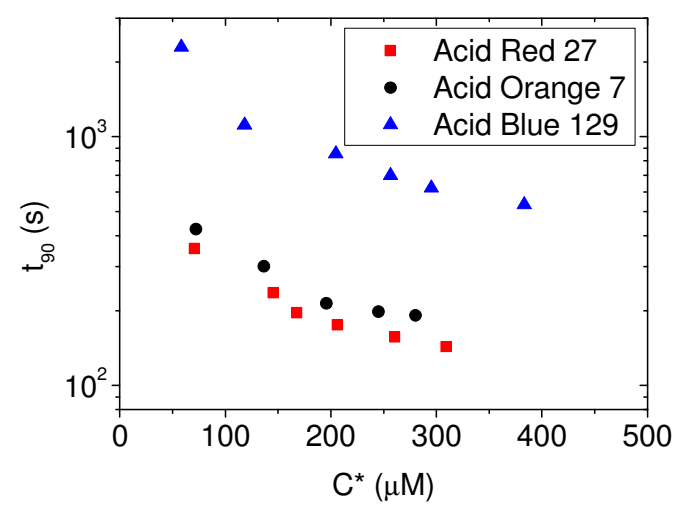

Fig. 9. Time at $90 \%$ conversion for the different dyes at different input ozone gas concentrations. The initial concentrations are $[\mathrm{AB} 129]_{0}=65.9 \mu \mathrm{M}$; $[\mathrm{AO} 7]_{0}=40 \mu \mathrm{M} ;[\mathrm{AR} 27]_{0}=30 \mu \mathrm{M} . \mathrm{T}=$ $21.2^{\circ} \mathrm{C},\left[\mathrm{HClO}_{4}\right]=0.01 \mathrm{M},[\mathrm{t}-\mathrm{BuOH}]=$ $0.01 \mathrm{M}$

The Fig. 10 shows the estimated values of the parameter $p_{5}$ against the ozone saturation concentration; the data are shown in a double logarithmic plot for clarity, where the slopes of the lines are all equal to one. In a linear representation, not shown here, the kinetic rate constant is given by the slope of the lines. From Fig. 10 we conclude that the reaction rate decreases in the order AR27 > AO7 > AB129. After the Fig. 9 we could expect that the kinetic rate constants of AR27 and AO7 are close each other, because $t_{90}$ is almost the same. However, the shape of the dye abatement curves, which provides the $t_{90}$, is related both with the kinetic rate constant and the initial dye concentration. The closeness of $t_{90}$ for AR27 and AO7 is justified when the $p_{5}$ calculated for each dye are both compared. Furthermore, the obtained kinetic rate constants differ several orders of magnitude from those given in the bibliography, as it can be observed in Table II, where a recompilation of studies of azo dyes ozonation has been done. Numerical simulations were done using some referenced kinetic constants showing that they are not able to reproduce our experimental observations. The origin of this discrepancy could be related with the fact that these constants described in the bibliography are calculated through the determination of the experimental enhancement factors which lead to an overestimation of the kinetic rate constants. Moreover, a kinetic rate constant so high is near the diffusion controlled kinetic rate constants (Espenson, 2002) which are typical for radical reactions but not for direct ozonation reactions. If we compare our values with the kinetic rate constants between the ozone and several organic compounds (Hoigne and Bader, 1983; von Gunten, 2003) we observe that rate constants above $10^{6} \mathrm{M}^{-1} \mathrm{~s}^{-1}$ are uncommon for 
direct reactions. Then, we can conclude that the kinetic rate constants for the tested substances must be below $2000 \mathrm{M}^{-1} \mathrm{~s}^{-1}$.

Table II. Kinetic rate constants for direct ozonation of different azo dyes

\begin{tabular}{|c|c|c|c|}
\hline Dye & CAS Number & $\begin{array}{c}2^{\text {nd }} \text { order kinetic rate } \\
\text { constant }\left(\mathrm{M}^{-1} \mathrm{~s}^{-1}\right)\end{array}$ & Study \\
\hline Acid Red 27 & $915-67-3$ & 1.75 & $\begin{array}{c}\text { Dachipally and } \\
\text { Jonnalagadda, } 2011\end{array}$ \\
\hline Acid Red 27 & $915-67-3$ & $6.8 \cdot 10^{5}$ & López et al., 2004 \\
\hline Acid Red 27 & $915-67-3$ & $1.62 \cdot 10^{3}$ & This work \\
\hline Acid Orange II & $633-96-3$ & $5.5 \cdot 10^{5}$ & López et al., 2004 \\
\hline Acid Orange 7 & $633-96-3$ & $1.20 \cdot 10^{4}$ & Gomes et al., 2010* \\
\hline Acid Orange 7 & $633-96-3$ & $6.09 \cdot 10^{2}$ & This work \\
\hline Acid Blue 129 & $6397-02-0$ & $4.9 \cdot 10$ & This work \\
\hline Acid Blue 45 & 2861-02-1 & $7.09 \cdot 10^{5}$ & Gomes et al., 2010* \\
\hline Acid Blue 62 & $4368-56-3$ & $2.68 \cdot 10^{5}$ & Gomes et al., 2010* \\
\hline Acid Green 25 & $4403-90-1$ & $1.66 \cdot 10^{5}$ & Gomes et al., 2010* \\
\hline Acid Green 27 & $6408-57-7$ & $1.56 \cdot 10^{5}$ & Gomes et al., 2010* \\
\hline Acid Red 118 & $83027-46-7$ & $1.20 \cdot 10^{6}$ & Gomes et al., 2010* \\
\hline Direct Yellow 4 & $3051-11-4$ & $1.71 \cdot 10^{5}$ & Gomes et al., 2010* \\
\hline Reactive Blue 81 & $75030-18-1$ & $4.5 \cdot 10^{7}$ & $\begin{array}{l}\text { Ledakowicz et al, } \\
2001 * *\end{array}$ \\
\hline Reactive Orange 16 & $12225-83-1$ & $2.5 \cdot 10^{5}$ & $\begin{array}{c}\text { Tizaoui and Grima, } \\
2011\end{array}$ \\
\hline
\end{tabular}

* Determined in a quench-flow test.

** Determined in a stopped-flow test.

\section{5.- Conclusions}

In this paper the determination of kinetic rate constants for three dyes has been performed in an heterogeneous reactor. With this aim, an unstationary gas-liquid reactive model has been obtained and used. To fit the model with experimental data to obtain the kinetic parameters, an optimization method based on Gauss-Newton algorithm has been used, but as the model is non-linear, the initial guesses for the algorithm are very important to assure an adequate convergence to a correct optimum. In order to estimate correctly the initial guesses, a methodology using artificial neural networks has been used. It has been found that the estimated pre-optimization values are very close to the final fitted parameters. 
The methodology used to determine the absolute kinetic rate constants in gasliquid medium allows the determination of kinetic rate constants of relatively fast reactions. For the azo dyes used in this work, the kinetic study of the ozonation in an homogenous reactor is virtually impossible due to the high reaction rates. Furthermore, this study contributes to the gas-liquid reactions knowledge because the obtained kinetic rate constants are consistent with the rate of direct ozonation in front of other studies. To verify this aspect, parallel kinetic studies will be performed with other techniques and the model will be revised in order to get the correct characterization of the gas phase.

\section{Acknowledgements}

JF acknowledges the support of the doctoral fellowship from the Universitat Politècnica de València (UPV-PAID-FPI-2010-04).

\section{Notation}

$a$

$C(t)$

$C^{*}$

$D$

$d_{32}$

E

$E_{i}$

$H_{I O A}$

$\mathrm{Ha}$

$k_{2}$

$k_{L} a$

$M$

$N$

$P$

$R$

$r_{32}$

$t$

$T$

V

$V_{B}$

$V_{\mathrm{C}}$
$=\frac{S}{V}=$ interfacial specific area $\left(\mathrm{m}^{-1}\right)$

$=$ molar concentration in the liquid phase $\left(\mathrm{mol} \mathrm{m}^{-3}\right)$

$=y_{A 0} \frac{P}{H_{I O A}}=$ saturation concentration in the liquid bulk $\left(\mathrm{mol} \mathrm{m}^{-3}\right)$

$=$ diffusion coefficient of the gas in the liquid film $\left(\mathrm{m}^{2} \mathrm{~s}^{-1}\right)$

$=$ bubble Sauter's mean diameter $(\mathrm{m})$

$=$ Enhancement factor

$=$ Instantaneous Enhancement factor

$=$ Henry constant recommended by the IOA $\left(\right.$ bar $\left.\mathrm{m}^{3} \mathrm{~mol}^{-1}\right)$

$=$ Hatta number

$=$ second order kinetic rate constant $\left(\mathrm{L} \cdot \mathrm{mol}^{-1} \cdot \mathrm{s}^{-1}\right)$

$=$ volumetric mass transfer coefficient for the gas $\left(\mathrm{s}^{-1}\right)$

$=$ number of experimental values for each observable variable

$=$ Number of sections in liquid film

$=$ pressure $($ bar $)$

$=$ universal gas constant $\left(8.314 \mathrm{~J} \mathrm{~K}^{-1} \mathrm{~mol}^{-1}\right)$

$=$ Sauter's mean radius $(\mathrm{m})$

$=$ time $(\mathrm{s})$

$=$ temperature $(\mathrm{K})$

$=$ volume of the liquid phase in the reactor $\left(\mathrm{m}^{3}\right)$

$=$ volume of the bottom chamber in the reactor $\left(\mathrm{m}^{3}\right)$

$=$ volume of the head-space at the upper part of the reactor $\left(\mathrm{m}^{3}\right)$ 


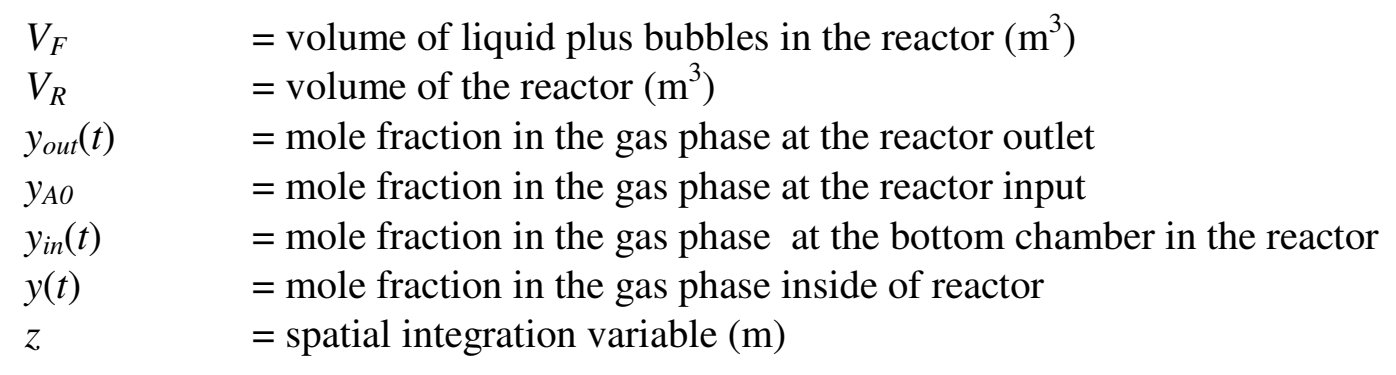

\section{Vectors and Matrices}

$\begin{array}{ll}\mathbf{S}_{\mathbf{k}} & =\text { Sensitity matrix (see eq. [30]) } \\ \mathbf{p} & =\text { unknown parameters vector defined in a model } \\ \mathbf{Q}_{\mathbf{k}} & =\text { weighting matrices in eq. [27] } \\ \hat{\mathbf{x}} & \quad \text { = vector of experimental observations } \\ \mathbf{x} & \quad=\text { vector of theoretical observable concentrations }\end{array}$

\section{Greek letters}

$\beta \quad=$ concentration ratio factor in eq. [2]

$\delta \quad=$ quiescent liquid film thickness (m)

$\varepsilon \quad=$ reactor gas hold-up

$\Phi=$ = objective function of optimization algorithm (eq. [27])

$v \quad=$ number of observable variables

$\xi \quad=$ diffusion coefficients ratio

\section{Subscripts and superscripts}

$b \quad=$ bulk of the liquid phase

$0 \quad=$ reactor inlet (gas phase) and/or initial concentration (liquid phase)

$A \quad=$ substance $A$ transferred from gas to liquid phase, associated to $\mathrm{O}_{3}$.

$B \quad=$ non-volatile substance $B$ in the liquid phase; associated to dye

\section{Keywords}

Ozone, Azo dyes, Acid Red 27, Acid Orange 7, Acid Blue 129, Ozonation, Mathematical modelling, Absolute kinetic rate constant determination, Artificial neural networks.

\section{References}

Beltrán, F.J., Ozone Reaction Kinetics for the Water and Wastewater Systems (Boca Raton, EEUU: Lewis Publishers, 2004).

Bin, A.K., “Ozone Solubility in Liquids”, Ozone Sci. Engr. 28: 67-75 (2006). 
Cardona, S.C., F. López, A. Abad, and J. Navarro-Laboulais, "On Bubble Column Reactor Design for the Determination of Kinetic Rate Constants in Gas-Liquid Systems", Can. J. Chem. Eng. 88: 491-502 (2010).

Chang, C.S., and G.T. Rochelle, "Mass Transfer Enhanced by Equilibrium Reactions", Ind. Eng. Chem. Fund. 21: 379-385 (1982) .

Dachipally, P., and S.B. Jonnalagadda, "Kinetics of ozone-initiated oxidation of textile dye, Amaranth in aqueous systems", J. Environ. Sci. Health. Part A 46: 46, 887897 (2011).

Danckwerts, P. V., Gas-Liquid Reactions (New York, EEUU: McGraw-Hill, 1970).

Das, A.K., and P.K. Das, "Bubble Evolution through a Submerged Orifice Using Smoothed Particle Hydrodynamics: Effect of Different Thermophysical Properties", Ind. Eng. Chem. Res. 48 (18): 8726-8735 (2009).

Doraiswamy, L.K., and M.M. Sharma, Heterogeneous reactions: Analysis, examples, and reactor design (New York, EEUU: Willey, 1984).

Englezos, P. and N. Kalogerakis, Applied parameter estimation for chemical engineers (New York, EEUU: Marcel Dekker, 2001).

Espenson, J.H., Chemical Kinetics and Reaction Mechanisms (New York, EEUU: McGraw-Hill, 2002).

Ferrell, R.T., and D.M. Himmelblau, "Diffusion Coefficients of Nitrogen and Oxygen in Water", J. Chem. Eng. Data 12 (1): 111-115 (1967).

Gerlach, D., N. Alleborn, V. Buwa, and E. Durst, "Numerical simulation of periodic bubble formation at a submerged orifice with constant gas flow rate", Chem. Eng. Sci. 62 (7): 2109-2125 (2007).

Glasscock D.A., and G.T. Rochelle, "Numerical Simulation of Theories for Gas Absorption with Chemical Reaction“, AIChE J. 35: 1271-1281 (1989).

Gomes, A.C., J.C. Nunes, and R.M.S. Simões, "Determination of fast ozone oxidation rate for textile dyes by using a continuous quench-flow system", J. Hazard Mater 178: 57-65 (2010).

Gupta, P., M.H. Al-Dahhan, M.P. Dudukovic, and P.L. Mills, "A novel signal filtering methodology for obtaining liquid phase tracer responses from conductivity probes", Flow Meas. Instrum. 11: 123-131 (2000).

Higbie, R., "The rate of absorption of a pure gas into a still liquid during short periods of exposure", Trans. Am. Inst. Chem. Eng. 31: 365-389 (1935).

Hoigné, J., and H. Bader, "Rate constants of the reaction of ozone with organic and inorganic compounds in water - I"; Water Res. 17: 173-183 (1983).

IAPWS, "IAPWS Release on Surface Tension of Ordinary Water Substance", (1994).

IAPWS, "Release on the IAPWS Formulation 2008 for the Viscosity of Ordinary Water Substance", (2008).

Jamialahmadi, M., M.R. Zehtaban, H. Muller-Steinhagen, A. Sarrafi, and J.M. Smith, "Study of bubble formation under constant flow conditions", Chem. Eng. Res. Des. 79 (A5): 523-532 (2001).

Johnson, P.N., and R.A. Davis, "Diffusivity of Ozone in Water", J. Chem. Eng. Data 41: 1485-1487 (1996). 
King, C.J., "Turbulent Liquid Phase Mass Transfer at a Free Gas-Liquid Interface", Ind. Eng. Chem. Fund. 5: 1-8 (1966).

Ledakowicz, S., R. Maciejewska, J. Perkowski, and A. Bin, "Ozonation of Reactive Blue 81 in the bubble column", Water Sci. Technol. 44: 47-52 (2001).

Lewis, W.K. and, W.G. Whitman, "Principles of gas absorption", J. Ind. Eng. Chem. 16: 1215-1220 (1924).

López, A., H. Benbelkacem, J.S. Pic, and H. Debellefontaine, "Oxidation pathways for ozonation of azo dyes in a semi-batch reactor: A kinetic parameters approach", Environ. Technol. 25 (3): 311-321 (2004).

Meldon, J.H., O.O. Olawoyin, and D. Bonanno, "Analysis of mass transfer with reversible chemical reaction“, Ind. Eng. Chem. Res. 46: 6140-6146 (2007).

Navarro-Laboulais, J., S.C. Cardona, J.I. Torregrosa, J.I., A. Abad, and F. López, "Structural identifiability analysis of the dynamic gas-liquid film model", AIChE J. 52 (8): 2851-2863 (2006).

Navarro-Laboulais, J., S.C. Cardona, J.I. Torregrosa, J.I., A. Abad, and F. López, "Practical identifiability analysis in dynamic gas-liquid reactors optimal experimental design for mass-transfer parameters determination", Comp. Chem. Eng. 32 (10): 2382-2394 (2008).

Rapp, T. and U. Wiesmann, "Ozonation of C.I. Reactive Black 5 and Indigo", Ozone Sci. Eng. 29: 493-502 (2007).

Tanaka, M., G. Girard, R. Davis, A. Peuto, and N. Bignell, "Recommended table for the density of water between 0 degrees $C$ and 40 degrees $C$ based on recent experimental reports", Metrologia 38 (4): 301-309 (2001).

Tizaoui, C. and N. Grima, "Kinetics of the ozone oxidation of Reactive Orange 16 azo-dye in aqueous solution", Chem. Eng. J. 173: 463-473 (2011).

von Gunten, U., “ Ozonation of drinking water: Part I. Oxidation kinetics and product formation", Water Res. 37: 1443-1467 (2003).

Zwillinger, D., Handbook of differential equations 3rd ed. (San Diego, EEUU: Academic Press, 1998). 